\title{
On Principally Generalized Lifting Modules
}

\author{
Aseel Amer Hassan \\ Department of Mathematics, College of Science, University of Baghdad, Baghdad-Iraq. \\ Corresponding Author: aselamer16@gmail.com.
}

\begin{abstract}
In this paper we introduce principally generalized lifting as a generalization of principally lifting modules and we prove under certain conditions some relations between Mj-projective (quasidiscrete) and PGD 1 . [DOI: 10.22401/JNUS.20.4.14]
\end{abstract}

Keywords: lifting modules, principally lifting modules, principally generalized lifting modules.

\section{$\delta_{1}$ Introduction}

Let $\mathrm{R}$ be an associative ring with identity and let $\mathrm{M}$ be a unital $\mathrm{R}$-module.A sub module $\mathrm{L}$ of an $\mathrm{R}$-module $\mathrm{M}$ is called small for(short $\mathrm{L}$ $\ll M)$, if $K+L \neq M$ for any proper sub module $\mathrm{K}$ of $\mathrm{M}$. A module $\mathrm{M}$ is called hollow, if every proper submodule of $\mathrm{M}$ is small in $\mathrm{M}$ [1]. A non zero module $M$ is called so- semi hollow, if each proper finitely generated sub module is small in $\mathrm{M}$, and a non zero module $\mathrm{M}$ is so- called $\mathrm{P}$-hollow, if each proper cyclic sub module is small in $\mathrm{M}$ [5].It is clear that every hollow is semi hollow and every semi hollow is $\mathrm{P}$ - hollow. A module $\mathrm{M}$ is called lifting (or has the condition $\mathrm{D}_{1}$ ), if for every submodule $\mathrm{L}$ of $\mathrm{M}$, there is a decomposition $\mathrm{M}=\mathrm{N} \oplus \mathrm{S}$ such that $\mathrm{N} \leq \mathrm{L}$ and $\mathrm{S} \cap \mathrm{L} \ll \mathrm{M}$ [2]. It was introduced in [3] that a module $\mathrm{M}$ is principally lifting module (or has $\mathrm{PD}_{1}$ ), if for all $\mathrm{m} \in \mathrm{M}, \mathrm{M}$ has a decomposition $\mathrm{M}=\mathrm{N} \oplus \mathrm{S}$ with $\mathrm{N} \leq \mathrm{mR}$ and $\mathrm{mR} \cap \mathrm{S} \ll \mathrm{M}$. $\mathrm{M}$ is said to have condition $\left(D_{2}\right)$ in case, if $B$ is a su module of $\mathrm{M}$ with $\mathrm{M} / \mathrm{B}$ is isomorphic to summand of $M$ then $B$ is a summand of $M$ [4]. A module $\mathrm{M}$ is called a discrete module, if it has the condition $\left(D_{1}\right)$ and $\left(D_{2}\right) . M$ is said to have the condition $\left(D_{3}\right)$ just in case of if $M_{1}$ and $\mathrm{M}_{2}$ are summand. Such that $\mathrm{M}_{1}+\mathrm{M}_{2}=\mathrm{M}$ then $M_{1} \cap M_{2}$ is a summand of $M$. A module $\mathrm{M}$ is called so- a quasi- discret module, if it has the condition $\left(\mathrm{D}_{1}\right)$ and $\left(\mathrm{D}_{3}\right)$. [4]

A modul $\mathrm{M}$ is so- called a generalized lifting module, if every submodule $\mathrm{L}$ of $\mathrm{M}$, there is a decomposition $\mathrm{M}=\mathrm{M}_{1} \oplus \mathrm{M}_{2}$ such that $\mathrm{M}_{1} \leq \mathrm{L}$ and $\mathrm{M}_{2} \cap \mathrm{L} \leq \operatorname{Rad}(\mathrm{M})$. As a generalization of Principally lifting module we introduce a principally generalized lifting module (for short $\mathrm{PGD}_{1}$ ). Where $\operatorname{Rad}(\mathrm{M})$ is the Jacobson radical of $M$. It is known that
$\operatorname{Rad}(\mathrm{M})$ equal the sum of all small submodules of M. [4]. In this paper we study the relation between $\mathrm{PD}_{1}$ and $\mathrm{PGD}_{1}$ modules and prove some properties of a $\mathrm{PGD}_{1}$.

\section{$\delta_{2}$ P-hollows and the condiion $\left(\right.$ PGD $\left._{1}\right)$}

In this section we introduce $\mathrm{PGD}_{1}$ module as a generalization of $\mathrm{PD}_{1}$, that appeared in [3] and we prove results on $\mathrm{PGD}_{1}$ module.

We start by the following.

\section{Lemma (2.1) [5,2.15]:}

Let $\mathrm{M}$ be a module then

1. If $M$ is semi- hollow, then each factor modul is semi-hollow.

2. If $B \ll M$ and $M / B$ is semi-hollow then $\mathrm{M}$ is semi-hollow.

3. $\mathrm{M}$ is semi-hollow if and only if $\mathrm{M}$ is local or $\operatorname{Rad}(\mathrm{M})=\mathrm{M}^{\prime \prime}$.

\section{Proposition (2.2) [3]:}

The following are equivalent for a module $\mathrm{M}$.

1. $\mathrm{M}$ is $\mathrm{P}$ - hollow.

2. $\mathrm{B} \ll M$ when $M / B$ is a non Zero cyclic module ".

\section{Remark (2.3):}

1-P- hollow modules need no hollow just as is explained in [5] by considering the set $\mathrm{Q}$ of all rational as $\mathrm{Z}$ - module $(\mathrm{Q} / \mathrm{Z})$ is no hollow while is no cyclic for all that proper sub modul K of Q.

2-"hollow module are indecomposable modules then the direct sums of hollow module are not hollows, while according to lemma (2.1), if $M={ }_{i} \in I \oplus P_{i}$, where $P_{i}$ are non-cyclical P-hollows for all $\mathrm{i} \in \mathrm{I}$, then $\mathrm{M}$ is $\mathrm{P}-$ hollow". 
Remark (2.4):

Every hollow module is lifting [6].

\section{Definition (2.5):-[5]}

A module $\mathrm{M}$ is called Principally lifting (or has $\left(\mathrm{PD}_{1}\right)$ ) if for all $\mathrm{m} \in \mathrm{M}, \mathrm{M}$ has a decomposition $\mathrm{M}=\mathrm{N} \oplus \mathrm{S}$ with $\mathrm{N} \leq \mathrm{mR}$ and $\mathrm{mR} \cap \mathrm{S} \ll \mathrm{M}$.

As generalization of definition (2.5) we introduce the following:

\section{Definition (2.6):-}

$\mathrm{M}$ is principally generalizd lifting (or has $\mathrm{PGD}_{1}$ ), If for all $\mathrm{m} \in \mathrm{M}, \mathrm{M}$ has a dcomposition $\mathrm{M}=\mathrm{A} \oplus \mathrm{B}$ with $\mathrm{A} \leq \mathrm{mR}$ and $\mathrm{mR} \cap \mathrm{B} \leq \mathrm{Rad}$ (M).

\section{Note:-}

hollow module $\rightarrow$ lifting module $\rightarrow$ principally lifting module $\rightarrow$ principally generalized lifting module.

Example (2.7):-

1. $\mathrm{Z}_{\mathrm{P}}^{\infty}$ is $\left(\mathrm{PGD}_{1}\right)$.

2. $\mathrm{Z}_{4}$ as $\mathrm{Z}$-module is $\left(\mathrm{PGD}_{1}\right)$.

3. $Z_{p}, p$ is prim number is $\mathrm{PGD}_{1}$.

4. $\mathrm{Z}$ as $\mathrm{Z}$ - module is not $\mathrm{PGD}_{1}$.

\section{Proposition (2.8):-}

The condition $\left(\mathrm{PGD}_{1}\right)$ is inherited by sum ands.

\section{Proof:}

Suppose that $\mathrm{M}$ have the condition $\mathrm{PGD}_{1}$, also $K \leq \oplus M$, if $k \in K$, when $M$ has a decomposition $\mathrm{M}=\mathrm{A} \oplus \mathrm{B}$ with $\mathrm{A} \leq \mathrm{kR}$ and $\mathrm{kR} \cap \mathrm{B} \leq \operatorname{Rad}(\mathrm{M})$, it follows that $\mathrm{K}=\mathrm{A} \oplus(\mathrm{K}$ $\cap \mathrm{B})$ and $\mathrm{kR} \cap(\mathrm{K} \cap \mathrm{B}) \leq \mathrm{kR} \cap \mathrm{B} \leq \operatorname{Rad}(\mathrm{M})$, so $k R \cap(K \cap B) \leq \operatorname{Rad}(K)($ due to $K \leq \oplus M)$. Therefore $\mathrm{K}$ has $\left(\mathrm{PGD}_{1}\right)$.

\section{Lemma (2.9):-}

The following are equivalent for an indecomposable module $\mathrm{M}$.

1- $\mathrm{M}$ has $\left(\mathrm{PGD}_{1}\right)$.

2- $\mathrm{M}$ is a P-hollow module.

\section{Proof:}

(1) $\Rightarrow$ (2) Suppose that $0 \neq m \epsilon M, R m$ is proper submodule of $\mathrm{M}$, then by (1) there exist decomposable $\mathrm{M}=\mathrm{N} \oplus \mathrm{S}$, with $\mathrm{N} \leq \mathrm{Rm}$ and $\mathrm{Rm} \cap \mathrm{S} \leq \operatorname{Rad}(\mathrm{M})$, because $\mathrm{M}$ is indcomposable.
Then either $\mathrm{S}=0$ or $\mathrm{N}=0$, if $\mathrm{S}=0$ then $M=N$, hence $M=R m$ (Contradiction) (since $R m$ is proper), hence $N=0$. Thus $M=S$ therefor $\mathrm{Rm} \cap \mathrm{S}=\mathrm{Rm} \cap \mathrm{M}=\mathrm{Rm} \leq \operatorname{Rad}(\mathrm{M})$ thus $\operatorname{Rm} \leq \operatorname{Rad}(M)$ hence $m \epsilon \operatorname{Rad}(M)$, $\mathrm{Rm} \ll$ M.[11].

(2) $\Rightarrow$ (1) Since M is P- hollow then for each proper cyclic sub module $\mathrm{mR}$ of $\mathrm{M}, \mathrm{mR} \ll \mathrm{M}$. thus $\mathrm{M}=0 \oplus \mathrm{M}$ and $0 \leq \mathrm{mR}, \mathrm{mR} \cap \mathrm{M}=\mathrm{mR}$ $\leq \operatorname{Rad}(\mathrm{M})$.

The following definition appeared in [7]

\section{Definition (2.10) :-}

[7] Suppose that $M$ is an R-module, if $\mathrm{N}, \mathrm{L} \leq \mathrm{M}$ and $\mathrm{M}=\mathrm{N}+\mathrm{L}$, then $\mathrm{L}$ is so- called generalized supplement of $\mathrm{N}$ just is case $\mathrm{N} \cap \mathrm{L} \leq \operatorname{Rad}(\mathrm{L}) . \mathrm{M}$ is called generalized supplemented or (briefly GS) in case each submodule $\mathrm{N}$ has a generalized supplement in M.

\section{Example (2. 11):-}

[8] Suppose that $M$ is a GS and $\operatorname{Rad}(M)$ be Noetherian or M satisfy A.C.C on small sub module, then $\mathrm{M}$ is a supplemented module.

\section{Lemma (2.12):-}

Suppose that $M$ has $\left(\mathrm{PGD}_{1}\right)$, then each cyclic submodule $\mathrm{mR}$ has a generalized supplemented $\mathrm{S}$ whichever is a summand of M.

\section{Proof:}

Let $\mathrm{mR} \leq \mathrm{M}$ then there exist $\mathrm{N} \leq \mathrm{mR}$ with $\mathrm{M}=\mathrm{N} \oplus \mathrm{S}$ and $\mathrm{mR} \cap \mathrm{S} \leq \operatorname{Rad}(\mathrm{M})$, hence $\mathrm{M}=$ $\mathrm{mR}+\mathrm{S}$ and $\mathrm{mR} \cap \mathrm{S} \leq \operatorname{Rad}(\mathrm{M})$, hence $\mathrm{S}$ is a GS of $\mathrm{M}$ and $\mathrm{S} \leq \oplus \mathrm{M}$.

\section{Lemma (2.13):-} M."

"The following are equivalent for a module

1- $\mathrm{M}$ has $\mathrm{PGD}_{1}$

2- Every one cyclic submodule $\mathrm{K}$ of $\mathrm{M}$ can be written as $K=N \oplus S$ with $N \leq \oplus M$ and $\mathrm{S} \leq \operatorname{Rad}(\mathrm{M})$.

3- Each $m \in M$ there exist principal ideals I and $\mathrm{J}$ of $\mathrm{R}$ such that $\mathrm{mR}=\mathrm{mI} \oplus \mathrm{mJ}$, where $\mathrm{mI} \leq \oplus \mathrm{M}$ and $\mathrm{mJ} \leq \operatorname{Rad}(\mathrm{M})$.

\section{Proof:}

(1) $\Rightarrow$ (2) clear.

(2) $\Rightarrow$ (1) Let $\mathrm{K}$ be a cyclic submodul of $\mathrm{M}$ then by(2) $\mathrm{K}=\mathrm{N} \oplus \mathrm{S}$ with $\mathrm{N} \leq \oplus \mathrm{M}$ and 
$\mathrm{S} \leq \operatorname{Rad}(\mathrm{M})$. Write $\mathrm{M}=\mathrm{N} \oplus \mathrm{N}^{\prime}$, it follow that $\mathrm{K}=\mathrm{N} \oplus \mathrm{K} \cap \mathrm{N}^{\prime}$.

Let $\pi: \mathrm{N} \oplus \mathrm{N}^{\prime} \rightarrow \mathrm{N}^{\prime}$ be the natural projection, we have $\mathrm{K} \cap \mathrm{N}^{\prime}=\pi(\mathrm{K})=\pi(\mathrm{N} \oplus$ $\mathrm{S})=\pi(\mathrm{S}) \leq \operatorname{Rad}(\mathrm{M})$. hence $\mathrm{M}$ has $\mathrm{PGD}_{1}$.

(2) $\Leftrightarrow(3)$ Clear.

$\S_{3}$ Results on $\mathrm{Mj}$ - projective (quasidiscrete) and $\mathrm{PGD}_{1}$ modules.

In this section we prove under certain conditions some relations between $\mathrm{Mj}$ projective (quasi- discrete) and $\mathrm{PGD}_{1}$ module.

We need the definition:

\section{Definition (3.1)[12]:-}

Let $\mathrm{M}=\bigoplus_{\mathrm{i} \in \mathrm{j}} \mathrm{H}_{\mathrm{i}}$, then $\mathrm{H}_{\mathrm{i}}$ is $\mathrm{H}_{\mathrm{j}}$-projective for each $\mathrm{i} \neq \mathrm{j}$, if every supplement $\mathrm{C}$ of $\mathrm{H}_{\mathrm{i}}$ in $\mathrm{M}$ is a direct summand.

\section{Lemma (3.2) [9,corollary 4.50]:-}

Let $\mathrm{M}=\bigoplus \mathrm{M}_{\mathrm{i}}$, where $\mathrm{M}_{\mathrm{i}}$ is hollow and $\mathrm{Mj}$-projective whenever $\mathrm{i} \neq \mathrm{j}$.Then $\mathrm{M}$ is a quasi- discrete module.

"It is known that each quasi - discrete module is a direct sum of hollow sub module unique up to isomorphism and is fully relatively projective".

\section{Proposition (3.3):-}

Suppose that $\mathrm{M}=\bigoplus_{\mathrm{i} \in \mathrm{j}} \mathrm{H}_{\mathrm{i}}$, where each $\mathrm{H}_{\mathrm{i}}$ is a hollow module and is $\mathrm{H}_{\mathrm{j}}$-projective $(\mathrm{j} \neq \mathrm{i})$. Then $\mathrm{M}$ has $\left(\mathrm{PGD}_{1}\right)$.

\section{Proof:}

Suppose that $\mathrm{K}$ is a cyclic sub module of $\mathrm{M}$, and there exists a finite subset $\mathrm{F}$ of $\mathrm{I}$ that $\mathrm{K} \leq \oplus_{\mathrm{i} \in \mathrm{F}} \mathrm{H}_{\mathrm{i}}$. By lemma (3.2), $\bigoplus_{\mathrm{i} \in \mathrm{F}} \mathrm{H}_{\mathrm{i}}$ is quasi discrete, thus $\mathrm{K}$ can be written as $\mathrm{K}=\mathrm{N} \oplus \mathrm{S}$ wherever $\mathrm{N} \leq \oplus \oplus_{\mathrm{i} \in \mathrm{F}} \mathrm{H}_{\mathrm{i}}$, hence $\mathrm{N} \leq \oplus \mathrm{M}$ and $\mathrm{S} \leq \operatorname{Rad}\left(\oplus_{\mathrm{i} \in \mathrm{F}} \mathrm{H}_{\mathrm{i}}\right)$. Therefore by lemma (2.13) $\mathrm{M}$ has $\mathrm{PGD}_{1}$ ).

\section{Proposition (3.4) :-}

Suppose that $\mathrm{M}$ is module with $\mathrm{PGD}_{1}$, if $\mathrm{M}=\mathrm{V}+\mathrm{W}$ such that $\mathrm{W} \leq \oplus \mathrm{M}$ and $\mathrm{V} \cap \mathrm{W}$ is cyclic, then $\mathrm{W}$ contains generalized supplemented of $\mathrm{V}$ in $\mathrm{M}$.

\section{Proof:}

Because $\mathrm{M}$ has $\mathrm{PGD}_{1}$ and $\mathrm{V} \cap \mathrm{W}$ is cyclic we have by lemma (2.13) $\mathrm{V} \cap \mathrm{W}=\mathrm{N} \oplus \mathrm{S}$, where $N \leq \oplus \mathrm{M}$ and $\mathrm{S} \leq \operatorname{Rad}(\mathrm{M})$, Since $\mathrm{W} \leq \oplus \mathrm{M}$, we have $\mathrm{S} \leq \operatorname{Rad}(\mathrm{W})$. Write
$\mathrm{W}=\mathrm{N} \oplus \mathrm{N}_{1}$. It follows that $\mathrm{V} \cap \mathrm{W}=\mathrm{N} \oplus(\mathrm{V}$ $\left.\cap \mathrm{W} \cap \mathrm{N}_{1}\right)=\mathrm{N} \oplus\left(\mathrm{V} \cap \mathrm{N}_{1}\right)$.

Let $\pi: \mathrm{N} \oplus \mathrm{N}_{1} \rightarrow \mathrm{N}$ be that natural projection. It follows that $\mathrm{V} \cap \mathrm{N}_{1}=\pi(\mathrm{N} \oplus$ $\left(\mathrm{V} \cap \mathrm{N}_{1}\right)=\pi(\mathrm{V} \cap \mathrm{W})=\pi(\mathrm{N} \oplus \mathrm{S})=\pi(\mathrm{S})$, hence $\pi(\mathrm{S}) \leq \operatorname{Rad}(\mathrm{M})$, hence $\mathrm{V} \cap \mathrm{N}_{1} \leq \operatorname{Rad}(\mathrm{M})$ such that $\mathrm{M}=\mathrm{V}+\mathrm{N}+\mathrm{N}_{1}=\mathrm{V}+\mathrm{N}_{1}$. Therefore $\mathrm{N}_{1}$ is generalized supplemented of $\mathrm{V}$ in $\mathrm{M}$ that is contained in $\mathrm{W}$.

\section{Corollary (3.5) :-}

Suppose that $\mathrm{M}$ is a module with $\mathrm{PGD}_{1}$ over a principally "ideal ring", if $\mathrm{M}=\mathrm{V}+\mathrm{mR}$, then $\mathrm{mR}$ contains a generalized supplemented of $\mathrm{V}$ in $\mathrm{M}$.

\section{Proof:}

By lemma(2.13) we have $\mathrm{mR}=\mathrm{N} \oplus \mathrm{S}$, wherever $\mathrm{N} \leq \oplus \mathrm{M}$ and $\mathrm{S} \leq \operatorname{Rad}(\mathrm{M})$, it follows that $\mathrm{M}=\mathrm{V}+\mathrm{N}$, hence by lemma (2.13) $\mathrm{N}$ is cyclic summand of $\mathrm{M}$, hence $\mathrm{V} \cap \mathrm{N}$ is a cyclic submodule of $\mathrm{M}$ and thus apply proposition (3.4).

\section{Lemma (3.6) :-}

Suppose that $\mathrm{M}$ is module such that $\mathrm{PGD}_{1}$, then each indcomposable cyclic submodule $\mathrm{C}$ of $\mathrm{M}$ is either small in $\mathrm{M}$ or a sum and of $\mathrm{M}$.

\section{Proof:}

"by lemma (2.13) we have $\mathrm{C}=\mathrm{N} \oplus \mathrm{S}$ with $\mathrm{N} \leq \oplus \mathrm{M}$ and $\mathrm{S} \leq \operatorname{Rad}(\mathrm{M})$, since $\mathrm{C}$ is indecompable either $\mathrm{C}=\mathrm{S}^{\prime \prime}$ or $\mathrm{C}=\mathrm{N}$, if $\mathrm{C}=\mathrm{S}$, then $\mathrm{C} \leq \operatorname{Rad}(\mathrm{M})$ since $\mathrm{C}$ is cyclic, then $\mathrm{C}=\mathrm{Rx} \leq \operatorname{Rad}(\mathrm{M})$, hence $\mathrm{x} \in \operatorname{Rad}(\mathrm{M})$ imples $\mathrm{C}=\mathrm{Rx}$ is small in $\mathrm{M}$. If $\mathrm{C}=\mathrm{N}$, then $\mathrm{C} \leq \oplus \mathrm{M}$.

\section{Definition (3.7):-}

[4] "A module $\mathrm{M}$ is said to be $\pi$ projective, if for every two submodule U,V of $M$ with $M=U+V$,there exist $f \in \operatorname{End}(M)$ with $\operatorname{Imf} \leq \mathrm{U}$ and $\operatorname{Im}(1-\mathrm{f}) \leq \mathrm{V}^{\prime \prime}$.

\section{Lemma (3.8):-}

$[9,4.47][10,3.2]$ let $\mathrm{M}=\mathrm{M}_{1} \oplus \mathrm{M}_{2}$."Then following are equivalent."

1- $\mathrm{M}_{1}$ is $\mathrm{M}_{2-}$ projective.

2- If $\mathrm{M}=\mathrm{N} \oplus \mathrm{M}_{2}$, and $\mathrm{N} \cap \mathrm{M}_{2} \leq \oplus \mathrm{N}$ hence $M=N_{1} \oplus M_{2}$, wherever $N_{1} \leq N$. 


\section{Proposition (3.9):-}

Let $\mathrm{M}=\bigoplus_{\mathrm{i}=1} \mathrm{P}_{\mathrm{i}}$, where the $\mathrm{P}_{\mathrm{i}}$ are local modules for all $\mathrm{i}$, if $\mathrm{M}$ has $\left(\mathrm{D}_{3}\right)$,"then the following are equivalent".

1- $\mathrm{M}$ has $\mathrm{PGD}_{1}$

2- "M is a quasi-discrete module".

\section{Proof:}

(1) $\Rightarrow$ (2) Because $\mathrm{PGD}_{1}$ and $\mathrm{D}_{3}$ are inherited by summand, we have $\mathrm{p}_{\mathrm{i}} \oplus \mathrm{p}_{\mathrm{j}}$ has PGD $_{1}$ and $\mathrm{D}_{3}$ for all $\mathrm{i}, \mathrm{j}(\mathrm{i} \neq \mathrm{j})$.

If $P_{i} \oplus P_{j}=K+P_{j}$, then $P_{i} \cong\left(P_{i} \oplus P_{j}\right) / P_{j}=$ $\left(\mathrm{K}+\mathrm{P}_{\mathrm{j}}\right) / \mathrm{P}_{\mathrm{j}} \cong \mathrm{K} /\left(\mathrm{K} \cap \mathrm{P}_{\mathrm{j}}\right)$ is a cyclic module. Thus form some $m \in P_{i} \oplus P_{j}$

$\mathrm{K}=\mathrm{mR}+\left(\mathrm{K} \cap \mathrm{P}_{\mathrm{j}}\right)$. By $\mathrm{PGD}{ }_{1}$ for $\mathrm{P}_{\mathrm{i}} \oplus \mathrm{P}_{\mathrm{j}}$ and by lemma (2.13) we get $\mathrm{mR}=\mathrm{N} \oplus \mathrm{S}$ with $\mathrm{N} \leq \oplus \mathrm{P}_{\mathrm{i}} \oplus \mathrm{P}_{\mathrm{j}}$, So $\mathrm{S} \leq \operatorname{Rad}\left(\mathrm{P}_{\mathrm{i}} \oplus \mathrm{P}_{\mathrm{j}}\right)$ hence $\mathrm{P}_{\mathrm{i}} \oplus \mathrm{P}_{\mathrm{j}}=\mathrm{K} \oplus \mathrm{P}_{\mathrm{j}}=(\mathrm{N} \oplus \mathrm{S})+\left(\mathrm{K} \cap \mathrm{P}_{\mathrm{j}}\right)+\mathrm{P}_{\mathrm{j}}=$ $\mathrm{N}+\mathrm{P}_{j}$ and by $\left(\mathrm{D}_{3}\right)$ for $\mathrm{P}_{\mathrm{i}} \oplus \mathrm{P}_{\mathrm{j}}$, we have $\mathrm{P}_{\mathrm{i}} \oplus \mathrm{P}_{\mathrm{j}}$ $=\mathrm{N}+\mathrm{P}_{\mathrm{j}}$ with $\mathrm{N} \leq \mathrm{K}$. Hence by lemma (3.8) $\mathrm{P}_{\mathrm{i}}$ is $\mathrm{P}_{\mathrm{j}}$-projective for all $\mathrm{i} \neq \mathrm{j}$, therefor by lemma (3.2), $\mathrm{M}$ is quasi- discrete.

$(2) \Rightarrow(1)$ it is obvious.

\section{Proposition (3.10):-}

Suppose that $\mathrm{M}$ is a module over a local ring $\mathrm{R}$. If $\mathrm{M}$ has $\mathrm{PGD}_{1}$, then a cyclic submodule of $M$ is either small in $M$ or a summand of $\mathrm{M}$.

\section{Proof:}

"The proof follows from lemma (3.6) and the fact that every cyclic module over a local ring is a local module".

\section{Definition (3.11)[3]:-}

Suppose that $\mathrm{M}_{1}$ and $\mathrm{M}_{2}$ be $\mathrm{R}$-modules $\mathrm{M}_{1}$ is said to be Pprojective relative to $\mathrm{M}_{2}$ (or $\mathrm{M}_{1}$ is $M_{2^{-}}$Pprojective), if for each $m_{2} \in M_{2}$ epimorphism $\mathrm{g}: \mathrm{m}_{2} \mathrm{R} \rightarrow \mathrm{m}_{2} \mathrm{R} / \mathrm{K}$ and each homomorphism $\varphi: M_{1} \rightarrow m_{1} R / K$, there exists a homomorphism $\mathrm{f}: \mathrm{M}_{1} \rightarrow \mathrm{m}_{2} \mathrm{R}$ with $\mathrm{g} \circ \mathrm{f}=\varphi$.

\section{Remark (3.12) [3]:-}

Cleary every $\mathrm{M}$ - projective module is $\mathrm{M}$ - $\mathrm{P}$ projectiv, if $\mathrm{M}$ is a cyclic module then each $\mathrm{M}$ - Pprojective modul is $\mathrm{M}$ - projective module, there are R-modules $\mathrm{M}_{1}$ and $\mathrm{M}_{2}$, where $M_{1}$ is $M_{2}$ - Pprojective whilist $M_{1}$ is no $\mathrm{M}_{2}$-projective. Example $\mathrm{M}_{1}=\mathrm{Q}$ (the set of all rational number) $\mathrm{R}=\mathrm{Z}$ and $\mathrm{M}_{2}=\bigoplus_{\mathrm{i} \in \mathrm{I}} \mathrm{Z}$, where $f: \bigoplus_{i \in I} Z \rightarrow Q$ is an epimorphism (as $\mathrm{Q}$ is a homomorphic image of a free
Z-module). Clearly $\mathrm{Q}$ is $\bigoplus_{\mathrm{i} \in \mathrm{F}} \mathrm{Z}$ - projective for every finite subset $F$ of $I$, hence $Q$ is $\left(\bigoplus_{i \in I} Z\right)-P$ projective, while $\mathrm{Q}$ is not $\left(\bigoplus_{\mathrm{i} \in \mathrm{I}} \mathrm{Z}\right)$-projective, since $f$ does not split (due to $Q$ not a projective Z-module).

\section{Lemma (3.13):-}

Let $\mathrm{M}=\mathrm{M}_{1} \oplus \mathrm{M}_{2}$ be an R-module. Then the following are equivalent".

1- $\mathrm{M}_{1}$ is $\mathrm{M}_{2}$-Pprojective

2- $M_{1}$ is $m_{2} R$ - projective for all that $\mathrm{m}_{2} \in \mathrm{M}_{2}$

For all $m_{2} \in M_{2}$, if $M_{1} \oplus m_{2} R=m_{2} R+Y$, then there is $\mathrm{L} \leq \mathrm{Y}$ such that $\mathrm{M}_{1} \oplus \mathrm{m}_{2} \mathrm{R}=\mathrm{L}$ $\oplus \mathrm{m}_{2} \mathrm{R}$.

\section{Proof:}
$(1) \Rightarrow \quad(2)$ by definition of relative Pprojective
(2) $\Rightarrow$ (3) by lemma (3.8)
(3) $\Rightarrow$ (1) by lemma(3.8)

\section{Corollary (3.14):-}

Let $\mathrm{M}=\mathrm{M}_{1} \oplus \mathrm{M}_{2}$ a module over local ring R- module $\mathrm{M}_{1}$ and $\mathrm{M}_{2}$ are relatively Pprojective in that case $\mathrm{M}$ has $\mathrm{PGD}_{1}$, if and only if every one $\mathrm{M}_{1}$ and $\mathrm{M}_{2}$ have $\mathrm{PGD}_{1}$.

\section{Proof:}

$\Leftarrow)$ Suppose that $\mathrm{C}$ are arbitrary cyclic submodule of $\mathrm{M}$ then $\mathrm{C}=\left(\mathrm{m}_{1}+\mathrm{m}_{2}\right) \mathrm{R}$, where $\mathrm{m}_{1} \in \mathrm{M}_{1}, \mathrm{~m}_{2} \in \mathrm{M}_{2}$, since $\mathrm{M}_{1}$ and $\mathrm{M}_{2}$ have $\mathrm{PGD}_{1}$, then we have nothing to prove either $\mathrm{m}_{1}=0$ or $\mathrm{m}_{2}=0$.

Now to avoid triviality we may consider $\mathrm{C}$ is not a small submodule of $M$ since $C=\left(m_{1}+m_{2}\right) R \leq m_{1} R+m_{2} R$, we have $m_{1} R$ or $m_{2} R$ is not small in $M$. Without loss of generality we may assume $m_{1} R$ is no small in $\mathrm{M}$, hence it is not small in $\mathrm{M}_{1}$ by pro position (3.10), $m_{1} R$ is a summand of $M_{1}$ and hence $\mathrm{m}_{1} \mathrm{R}$ is $\mathrm{M}_{2}$-Pprojective hence $\mathrm{m}_{1} \mathrm{R}$ is $\mathrm{m}_{2} \mathrm{R}$ projective.

Since $m_{1} R \oplus m_{2} R=\left(m_{1}+m_{2}\right) R+m_{2} R$, we have by lemma (3.13) that there is $\mathrm{N} \leq\left(\mathrm{m}_{1}\right.$ $\left.+\mathrm{m}_{2}\right) \mathrm{R}$ with $\mathrm{m}_{1} \mathrm{R} \oplus \mathrm{m}_{2} \mathrm{R}=\mathrm{N} \oplus \mathrm{m}_{2} \mathrm{R}$.It follows that $\left(\mathrm{m}_{1}+\mathrm{m}_{2}\right) \mathrm{R}=\mathrm{N} \oplus\left[\left(\mathrm{m}_{1}+\mathrm{m}_{2}\right) \mathrm{R} \cap \mathrm{m}_{2} \mathrm{R}\right]$. "Since $\mathrm{C}$ is a local module and $\mathrm{m}_{2} \mathrm{R}$ is not contained in $\mathrm{C}$, we have that $\mathrm{C}=\mathrm{N}$. To show that $\mathrm{N}$ is a summand of $\mathrm{M}$. 
It is clear that" $\mathrm{m}_{1} \mathrm{R} \oplus \mathrm{M}_{2}=\mathrm{N}+\mathrm{M}_{2}$ and hence $\mathrm{N} \cap \mathrm{M}_{2}=\mathrm{N} \cap\left(\mathrm{N} \oplus \mathrm{m}_{2} \mathrm{R}\right) \cap \mathrm{M}_{2}=\left(\mathrm{m}_{1} \mathrm{R}\right.$ $\left.\bigoplus \mathrm{m}_{2} \mathrm{R}\right) \cap \mathrm{M}_{2} \cap \mathrm{N}=\mathrm{m}_{2} \mathrm{R} \cap \mathrm{N}=0$ (since $\mathrm{N}=\mathrm{C}$ ). As $\mathrm{m}_{1} \mathrm{R} \leq \oplus \mathrm{M}_{1}$, where $\mathrm{N} \oplus \mathrm{M}_{2}=\mathrm{m}_{1} \mathrm{R}$ $\oplus \mathrm{M}_{2} \leq \oplus \mathrm{M} \mathrm{C}=\mathrm{N} \leq \oplus \mathrm{M}$. Therefore $\mathrm{C} \oplus \mathrm{L}=\mathrm{M}$. The converse follows from proposition (2.8).

\section{References}

[1] Fleuery P. "Hollow modules, and local Endmorphism Ring, Pac". J. Math, (53), 379-385, 1974.

[2] Keskin D. "On lifting Modules, Comm. Algbra" 28(7), 3427-3440, 2000.

[3] Kamal M. and yousef A. "on principally lifting module" V.2, 127- 137, 2007.

[4] Wisbauer R. "Foundations of module and ring theory, Gordon and Breagh, Reading", 1991.

[5] Clark J. Lomp C. Vanaja N. and wisbauer R. "lifting modules, Brikhauser-Basel, Ist Edition", 2006.

[6] Ben A. laroussi hamdouni, "On lifting modules, University of Baghdad, The College of Science", A Thesis of MCS, 2001.

[7] Xue W. "Characterizations of Semi perfect and Perfect rings, Publications Matematiques", 40115-125, 1996

[8] Wang Y. and Ding N. "Generalized supplemented Modules", Taiwanese journal of Math, 10 (6), 1589-1601, 2006

[9] Mohamed S. and Muller B.J. "Continuous and discrete modules, Cambridge University Press", 1990.

[10] Kamal M. and yousef A. "On supplementation and generalized projective modules" to appear in J, Egyptain Math. Soc, 2013.

[11] Goodearl K.R. "Ring Theory, Pure and Applied Math.”, Marcel-Dekker.(33), 1976.

[12] Anderson F. W. and Fuller K.R. "Ring and Categories of Modules", Springer Verlage, New York. 1992. 